\title{
Applying ethics to itself: Recursive ethical questioning in architecture and second-order cybernetics
}

Ben Sweeting, University of Brighton.

July 2018

Author accepted manuscript. Accepted for publication in Kybernetes.

DOI: 10.1108/K-12-2017-0471

\begin{abstract}
Purpose: This article puts forward a way that ethics may be applied recursively to itself, in the sense that how we speak and reason about ethics is an activity to which ethical considerations and questions apply.
\end{abstract}

Design/methodology/approach: The article builds on parallels between design and cybernetics, integrating elements of ethical discourse in each field. The way that cybernetics and design can each act as their own meta-disciplines, in the design of design and the cybernetics of cybernetics, is used as a pattern for a similarly recursive approach to ethics. This is explored further by drawing parallels between Heinz von Foersters' criticism of moral codes and concerns about paternalism in designing architecture.

Findings: Designers incorporate implicit ethical questioning as part of the recursive process through which they design their design activity, moving between conversations that pursue the goals of a project and meta-conversations in which they question which goals to pursue and the methods they employ in doing so. Given parallels between designing architecture and setting out an ethics (both of which put forward ways in which others are to live), a similar approach may be taken within ethical discourse, folding ethics within itself as its own meta-discipline. 
Originality/value: The article provides a framework in which to address ethical considerations within ethical discourse itself. Recursive ethical questioning of this sort offers a way of coping with the incommensurability of values and goals that is commonplace given the fragmented state of contemporary ethics.

\section{Introduction}

There is a sense of confusion and fragmentation to contemporary ethics, understood here in the broad sense of the realm of thought and action concerned with the pursuit of the good. There is a lack of clarity over questions about values and standards of conduct, and also to the various discourses through which such values and standards are supported, questioned and applied. This extends even to the scope and status of ethics itself, which is understood in different ways in different contexts, sometimes in terms of the personal, sometimes as necessarily social or universal. Modern ethical debate has a tendency to collapse into the assertion and counter assertion of incommensurable first principles (Maclntyre, 1985). Even for matters where there is broad consensus as to something being fundamentally right or wrong, we often have no common view as to why this is the case (Eagleton, 2003, p. 229). While there is no shortage of potential frameworks or positions with which to resolve any specific question, this proliferation of possible responses presents its own difficulties. Depending whether an ethical question is framed in terms of duty, relationships, consequences, or character-and depending which theories, traditions, or other sources of authority are referred to in doing this-it may be answered very differently. This is reminiscent of the sort of ill-defined and uncertain situations that designers commonly encounter (Sweeting, 2018), where it has long been recognised that "the choice of explanation determines the nature of the problem's resolution" (Rittel and Webber, 1973, p. 166). Indeed, it may be that design can contribute to ethical enquiry. Caroline Whitbeck (2011), for instance, has suggested ways in which the practical ethical questions that designers face may be treated similarly to design questions more generally. Design may also contribute to normative and metaethical questions, and it is one such connection that I develop here. 
One way of building connections from design to ethics is via cybernetics. In the past decade there has been increasing interest in cybernetics amongst designers and in design amongst cyberneticians. The connection between the two fields runs deep. The circular, conversational processes that are the focus of cybernetics are characteristic of design activity, and are what make design distinctive as an approach to complex and ill-defined situations. As Ranulph Glanville (2007) has argued, design is a form of cybernetic conversation, and the two fields therefore complement each other such that "cybernetics is the theory of design and design is the action of cybernetics" (p. 1178). This close analogy makes it possible to connect ethical reflection within the field of cybernetics to design. For instance, cybernetic processes such as conversation involve, and can even be said to require, various ethical qualities and questions (Glanville, 2004). This can be extended to include conversational processes within design, as I have explored elsewhere (Sweeting, 2015; 2018). In this article, I develop a further connection between cybernetics, design and ethics in terms of another of the qualities of conversation that cybernetics shares with design: the ability to be applied recursively to itself (Glanville, 2007, p. 1183). I draw on this quality of design and cybernetics to understand ethics as being similarly recursive, such that ethical questions may be applied to the way we speak and reason about ethics. ${ }^{1}$

As normative ethical theories and moral codes are put forward on the basis that they give guidance as to ethically good actions, they do not generally invite further reflection on how they themselves are discussed or applied. It is easy to assume that if an ethical principle is true then it will justify the methods through which it is communicated to others. It might be argued, for instance, that if such and such an action is right or wrong then we are justified in persuading or even compelling others to act accordingly. The difficulty of addressing this point is, I suggest, an underlying reason for the "shrill tone" that can be observed when different ethical frameworks come into conflict with each other (Maclntyre, 1985, p. 8). 


\section{Ethics as its own meta-field}

Participants in conversations also engage in meta-conversations-that is, conversations about the conversation they are having. This allows them to steer the conversation, and to discuss and negotiate their differences (Glanville, 1996; 2011). Meta-conversations take the same form as the conversation they are about, and the two are often seamlessly interwoven, for instance where we question the direction of a conversation or try to confirm our understanding. Similarly, design can be applied to itself giving us the design of design. This occurs in various forms, for instance: where designers create technologies, methods or techniques that they or others will use to design with on future occasions; where professional designers design for the experience of others, given that the latter can be understood as a further (cybernetic, conversational) design activity (Glanville, 2006; Pask, 1969; Sweeting, 2011); and in the way that design involves recursive operations both in its core processes, where designers take the output of previous attempts as the input for new ones, and where, in research through design, it is used as a way of investigating itself (Glanville, 2014b). Both conversation and design are examples of cybernetic systems that can be applied to themselves, and this can also be said of the field of cybernetics: the process of observing or interacting with a cybernetic system is itself a cybernetic system. This observation led to cybernetics developing an understanding of itself in its own terms, usually referred to as the cybernetics of cybernetics, or second-order cybernetics (e.g. Glanville, 2002; Mead, 1968; Riegler et al., 2017; Umpleby, 2017; von Foerster, 1995; 2003c). ${ }^{2}$

In design and cybernetics this recursive quality has allowed forms of critique such that these fields can be understood and practiced in terms of their own designerly and cybernetic criteria. This is important for their disciplinary integrity and consistency. Design has a history of becoming distorted when understood in terms of theories imported from other fields (Glanville, 2014a). Cybernetics, understood as the study of circularity, requires its own circularities to be considered if it is to take circularity seriously (Glanville, 2002). A similar approach may be taken with ethics, in the sense that ethical discourse (in all its varieties) is an activity of which ethical questions may be asked. One way of understanding this is in terms of a hierarchy, either in the 
sense of the field of meta-ethics, which is concerned with theories about the meaning, nature and justification of ethical statements, or in the way that some theorists distinguish ethics as a regulator for morality (Luhmann, 1991; Thyssen, 1992). The sort of recursive operations that take place in design and cybernetics suggest that we could construct a different form of meta-ethical enquiry, where ethics, like design and cybernetics, operates as its own meta-field. This avoids a hierarchy: the cybernetics of cybernetics is still cybernetics; the design of design is still design; and ethical questioning of ethical questioning would still be ethical questioning. In this sense ethical considerations may be understood as entering the very discourse in which they are communicated and debated.

As with design and cybernetics, this raises questions of consistency, where the assumptions and principles put forward in any particular ethical framework apply equally to the framework itself. An example of this is giving consideration to the consequences of consequentialist reasoning. Let us assume, for the moment, that consequentialism gives a true account of good action, putting aside other criticisms that might be advanced. The right action to take in some situation will be the one that achieves the best overall outcome. However, where this is used as a form of practical reasoning in a particular situation then there are further consequences that need to be taken into account. For instance, the promulgation of consequentialist reasoning can lead to the normalisation of moral bargaining, which may be used unscrupulously to provide justification for unethical acts. In order to be consistent, the use of consequentialist reasoning must therefore account not just for the specific instance under consideration but also for the consequences this reasoning has on wider ethical discourse.

While in design and cybernetics this recursive process is usually understood in terms of ensuring rigor, it also raises ethical issues. Designers and cyberneticians must address their principles to their own activities as well as to those of others (a formulation of the golden rule). ${ }^{3}$ In cybernetics this has led to a particular focus on responsibility, both in the sense of that we have for our own actions (Glanville, 1995; von Foerster, 2003a) and also in terms of the consequences that the field of cybernetics has had for society (Krippendorff, 2008; Mead, 1968). Similar 
questions can arise in the case of ethics, especially where different frameworks come into conflict with each other. A prominent example of recursive ethical questioning of this kind can be found in the second-order cybernetics of Heinz von Foerster (2003a), who criticises the language or moral codes in terms of ethical responsibility. ${ }^{4}$ Bernard Poerksen (2011) has summarised von Foerster's ethical concerns as an "ethics of enabling ethics"-as an "observation of modes of argumentation in the domain of ethics, which is itself in turn carried out with ethical intentions" ( $p$. 144).

It is difficult to build directly on von Foerster's position because it counsels us to keep ethics implicit (more on this below). In order to develop my argument, I therefore draw parallels between von Foerster's concerns and some aspects of architectural ethics. I refer to architecture partly because it is my own discipline, and partly because of the layered nature of ethical questions that it raises. These include the ethical status of buildings; the ethical ideas that buildings sometimes try to communicate or enact; and also the conduct of the processes through which buildings are designed and produced. This layering helps make visible some of the ethical considerations that apply to the processes of ethical discourse, and offers a way of both challenging and extending von Foerster's argument.

\section{The normative function of architecture}

One major contribution to ethical debates in architecture is that of philosopher Karsten Harries $(1975 ; 1987 ; 1997)$. Harries has suggested understanding architecture in analogy to ethics because of the way it puts forward a way of life or an ethos. Referring to Ludwig Wittgenstein's (2009) summary of philosophical questions as taking the form "I don't know my way about" (para 123), Harries characterizes the role of philosophy as helping us navigate profound uncertainties about how to live, a task with which architecture is also concerned (Harries, 1987, p. 29). Referring to this as architecture's "ethical function" (Harries, 1975; 1997), Harries attempts to recapture something of the moral and social mission of modernist architecture in contrast to the aesthetic orientation of postmodernism and the way that philosophy has tended to 
approach architecture as a branch of the philosophy of art. In doing so, Harries turns to phenomenology, the work of Martin Heidegger, and the theme of dwelling. As his argument develops it becomes entangled with some of the difficulties that come with these ideas, such as in characterising some communities as being more or less rooted or authentic than others (see e.g. the criticisms of architectural phenomenology advanced by Leach, 1998; 2005). My concern here, however, is not with the direction in which Harries develops his account but with where he starts it.

Harries' observation that architecture puts forward a way of life can be understood in much less escalated terms. There is a sense in which architecture, like an ethical theory or moral code, is normative. Just as moral codes or ethical theories such as utilitarianism put forward ways in which we are to act, so too architecture enables and leads to particular patterns of living, while limiting other possibilities. This includes where, as Harries advocates, architecture plays an active role in establishing identity, culture and community, but also the various social and spatial norms that architecture establishes within our everyday experience. Such norms may sometimes be explicitly moralising (Chan, 2015), but even the most neutral of spaces still establishes this neutrality as a norm of use. While such norms may not amount to the sort of ethos that Harries speaks of, they are nevertheless ethically significant in that they constitute part of the structure of our lives, and are often politically and socially charged. Consider, for instance, an everyday public space such as a café, or a communal circulation space within a housing project. The way that such spaces are set out implies certain patterns of use that are to be followed, and these in turn enable and restrict different forms of interaction with others or appropriations of space.

This impact of architecture on everyday life is often deliberate-after all, and as cybernetician Gordon Pask (1969) reminds us, it is social systems that architects are primarily concerned with, not just the "bricks and mortar" (p. 494). Yet, this impact is still significant where the consequences of architecture are different to what was intended (as is often the case), where such intentions are absent, or where attempts are made to avoid such effects. Gregory Bateson (2000, pp. 493-494), for instance, notes how the spatial organisation of a room for a lecture, something that is often done without much thought, may imply and reinforce the epistemological 
assumptions underlying the environmental crisis. Indeed, even architecture that is open or flexible enables this openness or flexibility as a particular condition, one that is consequential for the lives of those who inhabit it. Thus, it is possible to maintain Harries' premise that architecture and ethics coincide with each other in setting out a way of life, without committing to his wider argument about how architecture should do this.

\section{Implicit ethical questioning}

Architecture's normative function raises ethical questions not just about what norms it is to establish but also over how such decisions are to be taken. This is in part a matter of professional ethics, where particular standards of conduct are embodied in regulations or codes of practice. There are also tensions that arise because of the asymmetry of the situation, where agency over design decisions is primarily located with people other than those that are impacted by them. Most design questions cannot be resolved objectively because of their ill-defined and changeable nature, such that designers are responsible not just for their responses to questions but also for how they are framed (Rittel and Webber, 1973). This combination of ethical significance, contestability and asymmetry means that designers' own values can rebound onto others who do not share them. This is a part of the challenge of designing architecture and is not easily avoided. Designers must navigate this situation with care in order to avoid being paternalistic, while still acting with integrity with respect to their own principles (I return to ways in which designers do this below).

There are parallels between this and where ethical discourse becomes moralising, as per the criticisms that von Foerster (2003a) levels against moral codes. This parallel is not surprising, given the analogy that I have introduced above. If there is a sense in which we can see architecture and ethics in similar terms, as both putting forward ways of life, then the designing of architecture, in turn, sits parallel to the ways in which we speak and reason about ethics. That we can ask ethical questions of the former suggests that we might ask similar questions of the latter. 
Like Harries, von Foerster draws on Wittgenstein (his fellow Viennese), founding his argument on a quotation from the Tractatus: "it is clear that ethics cannot be articulated" (Wittgenstein, 1974, 6.421, von Foerster's own translation). When we describe an ethical principle, formulating it in a moral code or similar, this is oriented to what others should do rather than what this principle requires of us. This is to take a privileged position with respect to others, where we assume the authority to guide them in their actions, much like the asymmetrical relationship between designers and those they design for. Given the contestability of ethical premises, it is difficult to justify an authoritative position such as this. There is no clear way to resolve between alternative ethical frameworks where they come into conflict, much as there is no right answer to a design question. Given this contestability, the claims that moral codes make on others tend towards moralisation. Von Foerster (2003a) criticises this aspect of ethical discourse in terms of ethical responsibility: where we defer to moral codes given to us by others, we juggle away our own responsibility (p. 293); where we put forward moral codes, we concern ourselves with what others should do and distract ourselves from what ethics requires of us ( $p$. 289).

Von Foerster suggests that we keep ethics implicit in our action, associating this with the sort of circular and recursive processes with which cybernetics is concerned:

Let me continue with Wittgenstein, "It is clear however, that ethics has nothing to do with punishment and reward in the usual sense of the terms. Nevertheless, there must indeed be some kind of ethical reward and punishment, but they must reside in the action itself."

They must reside in the action itself! You may remember, we came across such self-referential notions earlier with the example, "A implies A" and its recursive relatives of second-order cybernetics. Can we take a hint from these comments for how to go about reflecting about ethics, and at the same time adhere to Wittgenstein's criterion [that ethics cannot be articulated]? I think we can. I myself try to adhere to the following rule; to master the use of my language so that ethics is implicit in any discourse I may have. (e.g., in science, philosophy, epistemology, therapy, etc.) 
What do I mean by that? By that I mean to let language and action ride on an

underground river of ethics, and to make sure that one is not thrown off. This insures that

ethics does not become explicit and that language does not degenerate into

moralizations.

Von Foerster puts forward two suggestions for how to achieve this, both of which stem from the second-order cybernetic observation that we are always participating in the world. The first concerns responsibility, and particularly how even frameworks such as objectivity, with which we understand limits on our responsibility, are things we are responsible for. The second concerns conversation, where we use language as a way of interacting with, understanding, and relating to others. For von Foerster, these provide a framework with which to address ethics within our actions, without needing to make it explicit.

It is difficult, however, to see how this stance can be maintained in complex social situations. There are, for instance, situations where ethical issues need to be addressed explicitly; where implicit values need to be opened to scrutiny; where not speaking out would lead to acquiescence rather than responsibility; or where our actions articulate ethics whichever way we compose our language. Von Foerster proposed qualifying statements as applying to oneselfreplacing "there is..." with "I think..." (Poerksen, 2003, p. 14) and "thou shalt..." with "I shall..." (von Foerster, 2003a, p. 289). I am not convinced that such an approach is successful in avoiding the articulation of ethics. Where I make claims in language about what I should do then these will often rebound onto others in the situation, such as where claims that I make about my own obligations are also applicable to others who are in a similar situation to me (see for instance von Foerster's discussion of the principle of relativity; von Foerster, 2003c, p. 227). There are also many situations, such as in design, where our responsibility includes responsibility for others and so cannot be confined to the personal.

Architects cannot keep ethics implicit because architecture itself is an articulation of a way of living. Nor does it help if they qualify their views as personal, as this makes the situation more moralising not less. There is not a straightforward way for architects to avoid the 
paternalistic structure of the situation in which they are engaged. As discussed above, it is desirable that architecture is ethically significant in its impact, making a difference to people's lives, and this significance is part of what makes its resolution contestable. This is the purpose of the discipline, and to retreat from it is to avoid some of the specific responsibilities that come with the role. It might be suggested that architects should defer to their clients rather than push their own agenda. However, the interests of clients and users (and indeed other stakeholders) are not necessarily aligned and even if they do coincide, as in a commission for a private house on an isolated site, architects have a duty to their clients to formulate design briefs not just to answer them. Participative design methods have been successful in many design disciplines but can be difficult to apply in architecture. The impact of a building extends beyond those immediately involved to include others who cannot be identified let alone consulted, such as passers by and future users.

While the example of designing architecture presents a challenge to the strategy of keeping ethics implicit, the way designers cope with this situation may help extend von Foester's position to situations where one cannot avoid articulating ethics. The core methods that designers use take a conversational form that, seen in cybernetic terms, implicitly involves a number of ethical considerations, including both the suggestions that von Foerster puts forward (Sweeting, 2018). These are part of the meta-conversations that occur within design activity, through which designers address the scope and methods of the project at hand.

Part of what is distinctive about the ways in which designers work is that they challenge the limits of the situations they encounter and reformulate them to create new opportunities. As well as the design conversations through which designers pursue the goals of a project, they engage in meta-conversations that question which goals to pursue; what to treat as within their scope and what as outside; which constraints and criteria to challenge and which to accept; and what stance to take towards the more explicit ethical issues involved. This process is crucial to designers because of the ill-defined nature of the situations in which they work, but it is significant that they also do this with what appear to be well-framed problems (Cross, 2007, p. 100; Thomas 
and Carroll, 1979). In so doing they become responsible for the assumptions and criteria contained within the briefs with which they are presented, taking responsibility for where their responsibility lies. Moreover, the conversational process through which this is carried out incorporates an implicit concern for others. This includes face-to-face conversations, consultations and other participatory events, but also the drawing and modelling through which designers develop and test ideas, for instance in the way architects "walk through" their plan drawings. This allows designers to think through the eyes of those they design for (c.f. von Foerster, 1991), anticipating the concerns of even unknown others.

As design conversations and meta-conversations take the same form-designers can be thought of as designing their design process-such considerations can be understood as integral parts of design rather than as acting as limits on it from the outside. They can even be regarded as requirements for design to be effective in practical terms, being present within characteristic design activities such as sketching (Glanville, 2007, pp. 1197-1198; Sweeting, 2018). This allows ethical issues, including questions over the privileged position that designers themselves occupy, to be raised from within design activity as it progresses. These will sometimes need to be addressed explicitly, but this can be approached gradually in much the same way as with other criteria that become clarified through design activity. In this interpretation, the call to keep ethics implicit applies not just to values and standards of conduct, but also to the questioning of such values and standards. This is important in the context of the ill-defined situations in which designers work, where many issues and conflicts cannot be foreseen at the outset. This is not to say that designers always do this, or that the results of such considerations will always be appropriate. Yet, while von Foerster's strategy of keeping ethics implicit can seem somewhat unrealistic, design can be understood as a way of acting in which this can be achieved to at least some extent in even complex and highly charged situations. 


\section{Conclusion}

In this article I have used the example of designing architecture to understand ethics as an activity that can be applied to itself. If architecture is understood as in some respect analogous to ethics, then designing architecture parallels the processes by which ethics is questioned and deliberated. That we can ask ethical questions of how the processes of designing architecture are conducted, not just of the outcomes of these processes, suggests that similar questions can be raised regarding how we speak and reason about ethics. One example of this sort of recursive approach to ethics is von Foerster's criticism of moral codes in terms of ethical responsibility. In order to develop this, I have drawn parallels with concerns about paternalism in designing architecture, where the agency for resolving ethically significant questions is held primarily with people other than those affected by them. This is in part regulated by professional ethical codes, but is also a product of the asymmetry of professionalism itself. The example of designing architecture presents a challenge to von Foerster's strategy of keeping ethics implicit as, in the end, architects cannot avoid articulating ethics, the purpose of architecture being to set out a way of living that will make a difference to others. It is difficult to bridge this asymmetry because of architecture's wide impact and the contestable nature of design questions. One way that designers cope with this is through incorporating implicit ethical questioning within core design activities as a form of meta-conversation, often without thinking of it in these terms. This includes taking responsibility for how they understand the extent of their responsibilities and using media such as drawing and modelling to think through the eyes of others who are not able to participate. While von Foerster's proposal that we keep ethics implicit can seem overly idealistic, the example of designing architecture provides an example of how this might be achieved to at least some extent even in complex situations. Given the parallels I have put forward, such an approach might also be extended to how we speak and reason about ethics, folding ethics into itself as its own meta-field. The inclusion of similar implicit ethical considerations within ethical discourse may be especially valuable where frameworks come into conflict, offering a way of coping with the incommensurability of values and goals that is commonplace given the fragmented state of contemporary ethics. 


\section{Acknowledgements}

This article was developed from a working paper presented at the Relating Systems

Thinking and Design conference held at OCAD University, Toronto, Canada (Sweeting, 2016). I

am grateful to the organisers of that conference and to all who have gave me comments following the presentation. My attendance at that conference was funded by the School of Architecture and Design at the University of Brighton. The foundation for the argument is developed from part of my $\mathrm{PhD}$ research, which was funded by the Arts and Humanities Research Council and supervised by Neil Spiller and Ranulph Glanville. I am especially grateful to Peter Jones, Elisa Lega, Catalina Mejía Moreno and Tanya Southcott for conversations and comments that have helped the development of these ideas and this text.

\section{References}

Bateson, G. (2000), Steps to an ecology of mind, University of Chicago Press, Chicago, IL. First Published: 1972.

Chan, J. (2015), "Moral agency in architecture? The dialectics of spatializing morality and moralizing spaces", in Müller, A.-L. and Reichmann, W. (Eds.), Architecture, materiality and society: Connecting sociology of architecture with science and technology studies, Palgrave-Macmillan, Basingstoke, UK, pp. 198-214.

Cross, N. (2007), Designerly ways of knowing, Birkhäuser, Basel.

Eagleton, T. (2003), Sweet violence: The idea of the tragic, Blackwell, Malden, MA.

Glanville, R. (1995), "Chasing the blame", in Lasker, G. (Ed.) Research on Progress-Advances in Interdisciplinary Studies on Systems Research and Cybernetics, IIASSRC, Windsor, ON.

Glanville, R. (1996), "Communication without coding: Cybernetics, meaning and language (how language, becoming a system, betrays itself)", MLN, Vol. 111 No. 3, pp. 441-62, available at: http://www.jstor.org/stable/3251022.

Glanville, R. (2002), "Second order cybernetics", in Parra-Luna, F. (Ed.) Systems science and cybernetics, EoLSS, Oxford.

Glanville, R. (2004), "Desirable Ethics", Cybernetics and Human Knowing, Vol. 11 No. 2, pp. 7788, available at: http://www.ingentaconnect.com/content/imp/chk/2004/00000011/00000002/art00007 (accessed 4 June 2015).

Glanville, R. (2006), "Design and mentation: Piaget's constant objects", The Radical Designist, Vol. 0, available at: http://www.iade.pt/designist/pdfs/000_05.pdf (accessed 3 June 2015).

Glanville, R. (2007), "Try again. Fail again. Fail better: The cybernetics in design and the design in cybernetics", Kybernetes, Vol. 36 No. 9/10, pp. 1173-206. doi: $10.1108 / 03684920710827238$

Glanville, R. (2011), "Introduction: A conference doing the cybernetics of cybernetics", Kybernetes, Vol. 40 No. 7/8, pp. 952-63. doi: 10.1108/03684921111160197

Glanville, R. (2014a), "Design prepositions", in The Black $B \infty x$, volume II Living in Cybernetic Circles:, Edition Echoraum, Vienna, pp. 239-52. (Reprinted from: Belderbos, M. \& Verbeke, J. (eds.), The Unthinkable Doctorate, pp. 115-126. Brussels: Sint Lucas, 2007.). 
Glanville, R. (2014b), "An irregular dodecahedron and a lemon yellow citroën", in The Black $B^{\infty} x$, volume II: Living in Cybernetic Circles, Edition Echoraum, Vienna, pp. 193-203.

(Reprinted from: Schaik, L. van (ed.) (2003), The Practice of Practice. Melbourne: RMIT Press.).

Harries, K. (1975), "The ethical function of architecture", Journal of Architectural Education, Vol. 29 No. 1 , pp. $14-15$. doi: $10.2307 / 1424319$

Harries, K. (1987), "Philosophy and the task of architecture", Journal of Architectural Education, Vol. 40 No. 2, pp. 29-30. doi: 10.2307/1424928

Harries, K. (1997), The ethical function of architecture, MIT Press, Cambridge, MA.

Krippendorff, K. (2008), "Cybernetics's Reflexive Turns", Cybernetics and Human Knowing, Vol. 15 No. 3-4, pp. 173-84.

Leach, N. (1998), "The dark side of the domus", The Journal of Architecture, Vol. 3 No. 1, pp. 3142. doi: $10.1080 / 136023698374297$

Leach, N. (2005), "Less aesthetics, more ethics", in Ray, N. (Ed.) Architecture and its ethical dilemmas, Taylor and Francis, London, pp. 135-42.

Luhmann, N. (1991), "Paradigm lost: On the ethical reflection of morality", Thesis Eleven, Vol. 29 No. 1, pp. 82-94.

Maclntyre, A. (1985), After virtue: A study in moral theory, 2nd corrected ed., Duckworth, London. First Published: 1981.

Mead, M. (1968), "The cybernetics of cybernetics", in von Foerster, H., White, J.D., Peterson, L.J. and Russell, J.K. (Eds.), Purposive Systems, Spartan Books, New York, NY, pp. 1-11.

Müller, K.H. and Riegler, A. (2014), "Second-order science: A vast and largely unexplored science frontier", Constructivist Foundations, Vol. 10 No. 1, pp. 7-15, available at: http://www.univie.ac.at/constructivism/journal/10/1/007.introduction.

Pask, G. (1969), "The architectural relevance of cybernetics", Architectural Design, Vol. 39 No. 9, pp. 494-96.

Poerksen, B. (2003), "'At each and every moment, I can decide who I am": Heinz von Foerster on the observer, dialogic life, and a constructivist philosophy of distinctions", Cybernetics and Human Knowing, Vol. 10 No. 3-4, pp. 9-26.

Poerksen, B. (2011), "Ethics of enabling ethics", Cybernetics \& Human Knowing, Vol. 18 No. 3-4, pp. 143-49, available at:

http://www.ingentaconnect.com/content/imp/chk/2011/00000018/F0020003/art00013 (accessed 3 June 2015).

Riegler, A., Müller, K.H. and Umpleby, S.A. eds. (2017), New horizons for second-order cybernetics, Series on knots and everything, World Scientific, Singapore.

Rittel, H. and Webber, M. (1973), "Dilemmas in a general theory of planning", Policy Sciences, Vol. 4, pp. 155-69.

Sweeting, B. (2011), "Conversing with drawings and buildings: From abstract to actual in architecture", Kybernetes, Vol. 40 No. 7/8, pp. 1159-65. doi:

$10.1108 / 03684921111160386$

Sweeting, B. (2015), "Conversation, design and ethics: The cybernetics of Ranulph Glanville", Cybernetics \& Human Knowing, Vol. 22 No. 2-3, pp. 99-105, available at: http://www.ingentaconnect.com/content/imp/chk/2015/00000022/F0020002/art00012.

Sweeting, B. (2016), "The ethics of ethics and the ethics of architecture", in Jones, P. (Ed.) Relating Systems Thinking and Design (RSD5) 2016 Symposium, 13-15 October, Systemic Design Research Network, Toronto, Canada, available at: http://systemicdesign.net/rsd-symposia/rsd5-2016/.

Sweeting, B. (2018), "Wicked problems in design and ethics", in Jones, P. and Kijima, K. (Eds.), Systemic design: Theory, methods, and practice, Springer Japan, Tokyo. doi: 10.1007/978-4-431-55639-8

Thomas, J.C. and Carroll, J.M. (1979), "The psychological study of design", Design studies, Vol. 1 No. 1, pp. 5-11. doi: 10.1016/0142-694X(79)90020-6

Thyssen, O. (1992), "Ethics as second order morality", Cybernetics and Human Knowing, Vol. 1 No. 1, pp. 31-47. 
Umpleby, S.A. (2017), "Second-Order Cybernetics as a Fundamental Revolution in Science", in New Horizons for Second-Order Cybernetics, World Scientific, Singapore, pp. 29-47. doi: 10.1142/9789813226265_0003

von Foerster, H. (1991), "Through the eyes of the other", in Steier, F. (Ed.) Research and reflexivity, Sage, London, pp. 63-75.

von Foerster, H. ed. (1995), Cybernetics of cybernetics: Or, the control of control and the communication of communication, 2nd ed., Future Systems, Minneapolis, MN. First Published: 1974.

von Foerster, H. (2003a), "Ethics and second-order cybernetics", in Understanding understanding: Essays on cybernetics and cognition, Springer-Verlag, New York, NY, pp. 287-304.

von Foerster, H. (2003b), "Objects: Tokens for (eigen-)behaviors", in Understanding understanding: Essays on cybernetics and cognition, Springer-Verlag, New York, NY, pp. 261-72.

von Foerster, H. (2003c), Understanding understanding: Essays on cybernetics and cognition, Springer-Verlag, New York, NY.

Whitbeck, C. (2011), Ethics in engineering practice and research, second ed., Cambridge University Press, Cambridge. First Published: 1998.

Wittgenstein, L. (1974), Tractatus logico-philosophicus, translated by Pears, D.F. and McGuinness, B.F., Routledge and Kegan Paul, London. First Published: 1921.

Wittgenstein, L. (2009), Philosophical investigations, 4th ed., translated by Anscombe, G.E.M., Hacker, P.M.S. and Schulte, J., Wiley, Chichester. First Published: 1953.

\footnotetext{
${ }^{1}$ By using "applied" or "applying" here and elsewhere in this article, I do not mean to suggest any sort of split between theory and practice, as can sometimes be implied by e.g. "applied ethics". I am echoing Margaret Mead's proposal that the Society for General Systems Research "apply the ideas on the basis of which [the] society was being formed to ITSELF", a suggestion she repeated to the American Society for Cybernetics (Mead, 1968). I have used "applied" rather than "enacted" as it has a broader range of meanings, encompassing the relevance (applicability) of ethics to itself and also where an ethical critique is made of another element of ethical discourse.

${ }^{2}$ This recursive quality has recently been re-emphasized under the heading of "second-order science" (Müller and Riegler, 2014).

${ }^{3}$ The golden rule is the principle of treating others as one wishes to be treated. It is found in some form in almost all religions and cultures.

${ }^{4}$ There is another form of recursion that von Foerster discusses in the context of ethics, where stable values may be formed in society through the way we see ourselves through the eyes of others (von Foerster, 1991; 2003b). It is important to note in the present context that this observation is descriptive rather than normative. That is, it is concerned with the values that members of a society happen to hold rather than with which values it would be right to aspire to. It seems at first sight that a constructivist position would blur this distinction. However, this requires the resolution of meta-ethical questions that are in principle undecidable: to declare that ethical criteria are what society negotiates them to be is to make a realist claim.
} 